\title{
Increase in Dye:Dendrimer Ratio Decreases Cellular Uptake of Neutral Dendrimers in RAW Cells
}

\author{
Sriram Vaidyanathan ${ }^{\dagger}$, Milan Kaushik ${ }^{\ddagger}$, Casey Dougherty ${ }^{\ddagger}$, Rahul Rattan $§$, Sascha N. \\ Goonewardena $^{\S, \|, \perp}$, Mark M. Banaszak Holl ${ }^{\dagger, \ddagger, \#}$, Janet Monano ${ }^{\nabla}$, and Stassi DiMaggio ${ }^{\nabla}$ \\ tDepartment of Biomedical Engineering, University of Michigan, 1107 Carl A Gerstacker Building, \\ 2200 Bonisteel Boulevard, Ann Arbor, Michigan 48109, United States \\ ‡Department of Chemistry, University of Michigan, 930 North University Avenue, Ann Arbor, \\ Michigan 48109, United States \\ $\S$ Michigan Nanotechnology Institute for Medicine and Biological Sciences, University of Michigan, \\ 9220 MSRB III, 1150 West Medical Center Drive, SPC 5648, Ann Arbor, Michigan 48109, United \\ States
}

"Division of Cardiovascular Medicine, Internal Medicine, University of Michigan, 1500 E Medical Center Drive, Ann Arbor, Michigan 48109, United States

${ }^{\perp}$ Veterans Affairs Health System, 2215 Fuller Road, Ann Arbor, Michigan 48105, United States

\#Macromolecular Science and Engineering, University of Michigan, 3062C H.H. Dow Building, 2300 Hayward Street, Ann Arbor, Michigan 48109, United States

${ }^{\nabla}$ Department of Chemistry, Xavier University of Louisiana, 1 Drexel Drive, New Orleans, Louisiana 70125, United States

\section{Abstract}

Neutral generation 3 poly(amidoamine) dendrimers were labeled with Oregon Green 488 (G3$\left.\mathrm{OG}_{\mathrm{n}}\right)$ to obtain materials with controlled fluorophore:dendrimer ratios $(\mathrm{n}=1-2)$, a mixture containing mostly 3 dyes per dendrimer, a mixture containing primarily 4 or more dyes per dendrimer $(n=4+)$, and a stochastic mixture $(n=4$ avg $)$. The UV absorbance of the dye conjugates increased linearly as $n$ increased and the fluorescence emission decreased linearly as $n$ increased. Cellular uptake was studied in RAW cells and HEK 293A cells as a function of the fluorophore:dendrimer ratio (n). The cellular uptake of $\mathrm{G}^{-}-\mathrm{OG}_{n}\left(n=3,4+, 4_{\mathrm{avg}}\right)$ into RAW cells was significantly lower than $\mathrm{G} 3-\mathrm{OG}_{n}(n=1,2)$. The uptake of $\mathrm{G} 3-\mathrm{OG}_{n}\left(n=3,4+, 4_{\text {avg }}\right)$ into HEK 293A cells was not significantly different from $\mathrm{G}_{3}-\mathrm{OG}_{1}$. Thus, the fluorophore:dendrimer ratio was observed to change the extent of uptake in the macrophage uptake mechanism but not in the HEK 293A cell. This difference in endocytosis indicates the presence of a pathway in the macrophage that is sensitive to hydrophobicity of the particle.

Correspondence to: Sascha N. Goonewardena; Mark M. Banaszak Holl; Stassi DiMaggio.

Supporting Information: The Supporting Information is available free of charge on the ACS Publications website at DOI: 10.1021/ acsbiomaterials.6b00308.

Notes: The authors declare no competing financial interest. 


\section{Graphical abstract}

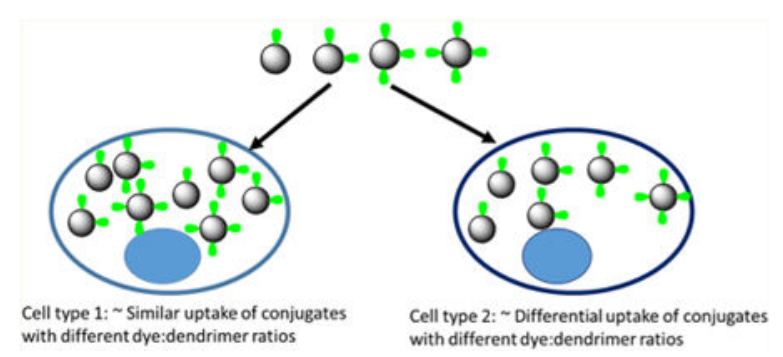

\section{Keywords}

PAMAM dendrimer; fluorescence emission; dye; mammalian cell; HPLC

\section{Introduction}

Cellular uptake of nanomaterials into macrophages is of great interest for both therapy and diagnosis because macrophages are thought to be involved in disorders such as atherosclerosis, ${ }^{1,2}$ stroke, ${ }^{3}$ type 1 diabetes, ${ }^{4}$ cerebral palsy,,${ }^{5,6}$ and cancer. ${ }^{7}$ Nanomaterials are taken up in most cells by endocytic pathways such as clathrin/caveolin mediated endocytosis as well as macropintocytosis. ${ }^{8}$ Macropinocytosis is especially active in immune cells such as macrophages and plays an important role in antigen processing. ${ }^{9-11}$ Macropinocytosis is also thought to play a role in the entry of pathogens in both macrophages as well as other cells. ${ }^{12,13}$ An important concept to consider for these endocytosis mechanisms is the formation of a protein corona around the nanomaterial that controls the uptake properties. ${ }^{14-17}$ Particle hydrophobicity can alter the corona and thus may alter relative uptake rates as a function of dye:dendrimer ratio. In addition, the hydrophobic dyes also serve as a model for varying the level of hydrophobic drug or targeting agent on the dendrimer, thus giving a broader relevance. ${ }^{18}$

Cellular uptake of nanomaterials is dependent on size, surface charge, chemistry, and shape. ${ }^{19}$ For example, Kannan et al. have shown that fluorescently modified neutral G4PAMAM dendrimer systems can be used to target neural glial cells in mice with cerebral palsy but not normal mice. ${ }^{5,6}$ Juliano et al. have shown that siRNA delivered using fluorescently labeled dendrimers show more uptake and knockdown activity than siRNA delivered using nonlabeled dendrimers. ${ }^{20}$ In addition, studies that characterize the cellular uptake of nanomaterials by macrophages often use fluorescently labeled nanomaterials such as dextran and iron as mechanistic probes. To best interpret the data from such studies, we need to consider two factors:

1. Stochastic conjugation to yield fluorescently labeled nanomaterials results in a mixture of fluorophore:nanoparticle ratios with very different photophysical properties. $^{21,22}$ The particles have a differing level of emission as a function of the dye:particle ratio. Accurate estimates of uptake require knowledge of the relative level of emission. ${ }^{22}$ 
2. Changes in hydrophobicity resulting as a function of dye:particle ratios can alter the cellular uptake of nanomaterials significantly. This is of particular concern for the use of stochastic mixtures, where fractionation could occur in the biological system and correlation to variation in photophysical properties is unknown. $^{22}$

In our previous study, the difference in uptake of cationic generation 5 poly(amidoamine) (G5 PAMAM) dendrimers was explored as a function of dye:dendrimer ratio for HEK 293A cells. ${ }^{22} \mathrm{We}$ are now exploring the impact of dye:dendrimer ratio upon the uptake of a neutral polymer, G3 PAMAM dendrimer, into macrophages dominated by macropinocytosis and HEK 293A cells. To address this question, we have investigated the effect of dye:dendrimer ratio on the photophysical properties and cellular uptake of neutral G3 PAMAM dendrimers labeled with controlled dye:dendrimer ratios of Oregon Green 488 (G3-OG $, n=1,2,3,4+$, $4_{\text {avg }}$ ). We tested cellular uptake into RAW cells (a mouse macrophage line) and HEK 293A cells (a human embryonic kidney line, possibly of adrenal cell origin). Our experiments show that the fluorescence emission of $\mathrm{G} 3-\mathrm{OG}_{n}$ is dependent on the OG:dendrimer ratio. For RAW cells, uptake decreased as the OG:dendrimer ratio increased. However, uptake into HEK 293A was not sensitive to OG:dendrimer ratios.

\section{Results and Discussion}

Heterogeneity of fluorescently labeled nanomaterials mixtures arises from the molecular weight distribution of the polymer/nanomaterial and the statistical distribution of dye:polymer ratios from the conjugation of a small molecule to a nanomaterial with many reactive sites. ${ }^{21-24}$ Although dendritic polymers have an intrinsically low polydispersity, they are still prone to molecular weight heterogeneity caused by defects, oligomerization, and trailing generations. ${ }^{25}$ For these experiments, monomeric G3- $\mathrm{NH}_{2}\left(\mathrm{mG} 3-\mathrm{NH}_{2}\right)$ was isolated from a mixture containing primarily monomer, dimer and trailing generations using reverse-phase high performance liquid chromatography (rp-HPLC). Monomeric G3- $\mathrm{NH}_{2}$ was then allowed to react with the succinimidyl ester of Oregon green 488 (OG) and acetylated using acetic anhydride such that the ratio of G3:OG in the solution was 1:4. This reaction resulted in a stochastic mixture of $\mathrm{G} 3-\mathrm{OG}_{n}(n=1,2,3,4+)$ as illustrated by the rpHPLC trace in Figure 1B. The stochastic mixture was separated using semipreparative rpHPLC to obtain $\mathrm{G} 3-\mathrm{OG}_{n}$ with controlled dye:dendrimer ratios. The composition and purity of the isolated fractions was determined by analytical rp-UPLC (Figure 1C), ${ }^{1} \mathrm{H}$ NMR spectroscopy (Figure S1), and MALDI-TOF MS (Figure S2). The predicted composition of the stochastic mixture based on a Poission distribution as well as the observed composition are given in Table 1. The predicted and observed fractions matched for $\mathrm{G} 3-\mathrm{OG}_{1}$ and G3$\mathrm{OG}_{2}$. The fraction of G3-OG 3 was higher than predicted by $\sim 5 \%$ and the fraction of G3$\mathrm{OG}_{4+}$ was lower by $5 \%$. The discrepancy is likely due to the incomplete separation obtained for these materials. The individual rp-UPLC traces illustrated in Figure 1C indicate good separation for $\mathrm{G} 3-\mathrm{OG}_{1}$. A small shoulder is present on the trace for $\mathrm{G} 3-\mathrm{OG}_{2}$; however, this likely arises from the presence of different regioisomers of dye binding, for example, two dyes on the same branch as opposed to different branches, as previously described. ${ }^{22}$ The trace for $\mathrm{G}_{3}-\mathrm{OG}_{3}$ also shows the presence of shoulder likely due to regioisomers but also clearly shows the presence of $\mathrm{G} 3-\mathrm{OG}_{2}$. The isolated material is about $3 \% \mathrm{G} 3-\mathrm{OG}_{1}, 19 \% \mathrm{G} 3-$ 
$\mathrm{OG}_{2}$, and $78 \% \mathrm{G} 3-\mathrm{OG}_{3}$ by the rp-UPLC analysis. $\mathrm{G}_{3}-\mathrm{OG}_{4+}$ material contains about $7 \% \mathrm{G} 3-$ $\mathrm{OG}_{2}$ and $25 \% \mathrm{G} 3-\mathrm{OG}_{3}$ along with about $68 \% \mathrm{G} 3-\mathrm{OG}_{4}$ and additional higher ratio conjugates.

The UV absorption and fluorescence of $\mathrm{G} 3-\mathrm{OG}_{n}(n=1,2,3,4+)$ were characterized in water (Figure 2). The intensity of UV absorbance increased with dye:dendrimer ratio (Figure S3). The intensity of UV absorbance for the stochastic sample was between that of $\mathrm{G} 3-\mathrm{OG}_{3}$ and $\mathrm{G} 3-\mathrm{OG}_{4+}$. The intensity of fluorescence emission from of $\mathrm{G} 3-\mathrm{OG}_{\mathrm{n}}$ decreased as $\mathrm{n}$ increased from 1 to $4+$. The fluorescence intensity of the stochastic sample was between the intensity of $\mathrm{G} 3-\mathrm{OG}_{2}$ and $\mathrm{G} 3-\mathrm{OG}_{3}$. The decrease in fluorescence and increase in UV absorption were linear as shown in Figure S3, indicating that the materials follow Beer's law despite the very large changes in local dye concentration, especially between $n=1$ and $n=$ 2. In previous studies using G5-TAMRA, G3-TAMRA and G5-Fluorescein conjugates, the UV absorption and fluorescence emission did not follow Beer's law. ${ }^{21-23}$ The linear behavior is surprising since the OG conjugates have a similar Stokes shift $(25 \mathrm{~nm})$ to that of fluorescein $(28 \mathrm{~nm})$, although it is greater than that of TAMRA $(15 \mathrm{~nm})$.

The cellular uptake of G3-OG was characterized in RAW cells and HEK 293A cells over a period of $24 \mathrm{~h}$ in the presence of $10 \%$ fetal bovine serum. Because the G3-OG conjugates have significantly different fluorescence intensities, the cellular uptake was corrected for emission differences. Based on raw fluorescence measurements, the uptake of G3-OG decreased with increasing dye:dendrimer ratio for both cells lines (Figure 3). For RAW cells, the uncorrected cellular uptake of $\mathrm{G} 3-\mathrm{OG}_{\mathrm{avg}}, \mathrm{G} 3-\mathrm{OG}_{2} \mathrm{G} 3-\mathrm{OG}_{3}$, and $\mathrm{G} 3-\mathrm{OG}_{4+}$ appeared to be significantly lower than the uptake of $\mathrm{G} 3-\mathrm{OG}_{1}$ as determined by one-way ANOVA followed by Games-Howell test. However, after correcting for the differences in fluorescence intensities, the cellular uptake of $\mathrm{G} 3-\mathrm{OG}_{3}, \mathrm{G} 3-\mathrm{OG}_{4+}$ and $\mathrm{G} 3-\mathrm{OG}_{\text {avg }}$ into RAW cells were significantly lower than $\mathrm{G} 3-\mathrm{OG}_{1}$ and $\mathrm{G} 3-\mathrm{OG}_{2}$. For HEK 293A cells, the uncorrected cellular uptake of $\mathrm{G} 3-\mathrm{OG}_{\mathrm{avg}}, \mathrm{G} 3-\mathrm{OG}_{3}$ and $\mathrm{G} 3-\mathrm{OG}_{4+}$ appeared to be significantly lower than the uptake of $\mathrm{G} 3-\mathrm{OG}_{1}$ and $\mathrm{G} 3-\mathrm{OG}_{2}$. However, the corrected fluorescence intensities of $\mathrm{G} 3-\mathrm{OG}_{3}, \mathrm{G} 3-\mathrm{OG}_{4}$ and $\mathrm{G} 3-\mathrm{OG}_{4 a v g}$ were not significantly different from $\mathrm{G} 3-\mathrm{OG}_{1}$. Thus, the dye:dendrimer ratio impacts the cellular uptake of G3-OG differently in different cell lines. A complete summary of statistical differences between groups for RAW and HEK 293A cells are presented in Tables S1-S4. The results presented here, along with previously published results ${ }^{22}$ show that stochastically labeled dendrimers can misrepresent cellular uptake to different degrees based on both cell type and dendrimer chemistry. Hence, it is important to quantify the photophysical properties of fluorescently labeled dendrimer materials when studying their cellular uptake.

For both cell lines, we also tested if the cellular uptake of the stochastic sample could be predicted by using a weighted average of the cellular uptake of the isolated G3-OG conjugates after correcting for differences in fluorescence intensities. The uptake of the stochastic sample could be predicted within error for both cell lines by weighting the cellular uptake of the individual species based on the fraction of the species in the stochastic sample as given in Table 1. After accounting for differences in fluorescence intensities, the predicted fluorescence uptake of the stochastic sample in RAW cells was 226000 . This was similar to 
the observed uptake of $233000 \pm 22000$. For HEK 293A cells, the predicted uptake of 47 000 was similar to the observed uptake of $47000 \pm 4000$.

Interestingly, these results are very different from the uptake of amine terminated cationic G5-PAMAM-TAMRA in HEK 293A cells in which the cellular uptake increased approximately 2-fold as the dye:dendrimer ratio increased. Moreover, the uptake of the stochastic material could not be predicted by using a weighted average of the uptake of the materials with precise dye dye:dendrimer ratio. The cellular uptake of cationic materials is mediated by adsorptive or cationic endocytosis. ${ }^{26}$ By way of contrast, cellular uptake of neutral materials on the order of $6 \mathrm{kDa}$ occurs via macropinocytosis, although other pathways have also been proposed to provide competitive levels of uptake. ${ }^{8,27}$

The controlled dye ratio dendrimers provide an interesting tool to probe the differences in uptake pathways in RAW and HEK 293A cells. Macropinocytosis, an active cellular pathway in both RAW and HEK 293A cells, is thought to be receptor independent and involve bulk engulfment of fluids into pinosomes. ${ }^{10}$ Such a mechanism would be expected to give uptake independent of G3:OG ratios, and also protein corona composition, ${ }^{14-17}$ and this is what was observed for the HEK 293A cells. The significant deviation in favor of uptake of the lower G3:OG ratios for RAW cells indicates that an active process is also present. Interestingly, the enhanced level of uptake cannot be simply explained by a passive interaction in which the higher ratio, more hydrophobic G3:OG species are more likely to adsorb to cell membranes since these materials actually show lower uptake. This data suggests that the differential uptake into RAW cells is controlled by a change in protein corona related to variation in G3:OG ratio. ${ }^{14-17}$ This sensitivity to the number of hydrophobic groups in the polymer is important since most dye and drug conjugations result in a more hydrophobic material. These results indicate that loading a polymer with more dye or drug, in an attempt to deliver a greater payload into the cell, has the potential to backfire by reducing the extent of cellular uptake. Recent studies have discussed the possibility of systematically varying dendrimer properties such as size, charge and chemical composition and understanding their influence on physiological interactions. ${ }^{28,29}$ Our results further highlight the need for more controlled studies to understand the influence of dendrimer surface modifications (e.g dye type, capping groups) on cellular interactions.

\section{Materials and Methods}

\section{Materials}

Biomedical grade G3 PAMAM dendrimer with ethylenediamine core was purchased from Dendritech Inc. and purified using rp-HPLC to give a molecular weight fraction free of trailing generations, dimers and higher oligomers. ${ }^{23}$ Trifluoroacetic acid, HPLC grade water, GE PD-10 sephadex column, and HPLC grade acetonitrile were purchased from FisherScientific and used as received. Oregon Green 488 was purchased from Life Technologies. A $500 \mathrm{MHz}$ Varian NMR instrument was used for all ${ }^{1} \mathrm{H}$ NMR measurements. All MALDITOF MS measurements were performed on a Bruker Ultraflex III with sinapinic acid matrix (Sigma-Aldrich) and sodium trifluoroacetate (Fischer Scientific) salt sample preparation. Serum-free DMEM (SFM) and RPMI from life technologies was employed for cell culture of HEK 293A cells, which were obtained from Life Technologies. Complete media was 
made by adding $50 \mathrm{~mL}$ of fetal bovine serum (FBS) and $5 \mathrm{~mL}$ of $100 \times$ of penicillinstreptomycin to $500 \mathrm{~mL}$ of SFM.

\section{Synthesis of G3-Ac-Oregon Green Conjugates (Stochastic Average = 4)}

Nine and a half milliliters of Oregon Green $488\left(1 \mathrm{mg} / \mathrm{mL}\right.$ DMSO, $\left.1.9 \times 10^{-5} \mathrm{~mol}\right)$ was added dropwise to a solution of G3 PAMAM monomer $\left(32.0 \mathrm{mg}, 4.6 \times 10^{-6} \mathrm{~mol}\right)$ in $0.2 \mathrm{M}$ $\mathrm{NaHCO}_{3}(8.0 \mathrm{~mL})$ over a period of $2 \mathrm{~h}$ by a syringe pump. The reaction mixture was left stirring at $20{ }^{\circ} \mathrm{C}$ for $24 \mathrm{~h}$. The product was purified by Sephadex G-25 column eluted with $0.1 \%$ TFA in water. The first band collected was dialyzed with a 3,500 MWCO membrane cassette against Milli-Q water for 3 days, exchanging washes every $2 \mathrm{~h}$. The purified dendrimer conjugate was lyophilized for 3 days to yield an orange powder material (36.53 $\mathrm{mg}, 92 \%)$. The orange solid $\left(36.53 \mathrm{mg}, 4.1 \times 10^{-6} \mathrm{~mol}, 1\right.$ equiv) was dissolved in anhydrous methanol $(20.0 \mathrm{~mL}), 0.0275 \mathrm{~mL}$ trimethylamine $\left(1.97 \times 10^{-4} \mathrm{~mol}, 48\right.$ equiv $)$ was added, and the mixture was stirred for $15 \mathrm{~min}$. Acetic anhydride $\left(0.0149 \mathrm{~mL}, 1.58 \times 10^{-4} \mathrm{~mol}, 38.4\right.$ equiv) was added slowly until the solution became transparent. The mixture was stirred at room temperature overnight. The solvent was removed under vacuum and the sample redissolved in 10× PBS $(8.0 \mathrm{~mL})$ and purified using dialysis cassettes with a 3,500 MWCO against $1 \times$ PBS buffer three times followed by Milli-Q water three times. The purified material was lyophilized for 3 days to yield an orange powder (34.5 mg, 88\% yield).

\section{Isolation of Controlled Ratio G3-OG $n(n=1,2,3,4+)$}

Semi-preparative rp-HPLC was performed on Waters Delta 600 HPLC system equipped with a Waters 2998 photodiode array detector, a Waters 2707 autosampler, and Waters Fraction collector III. The instrument was controlled by Empower 2 software. For isolation of the conjugates, a C5 silica-based rp-HPLC column $(250 \times 10.0 \mathrm{~mm}, 300 \AA)$ connected to a C5 guard $(10 \times 10 \mathrm{~mm})$ was used. The mobile phase for elution of the conjugates was a linear gradient beginning with 100:0 (v/v) water/ACN and ending with 20:80 (v/v) water/ACN over $30 \mathrm{~min}$ at a flow rate of $2.75 \mathrm{~mL} / \mathrm{min}$. TFA at $0.14 \mathrm{wt} \%$ concentration in water as well as in $\mathrm{ACN}$ was used as a counterion to make the dendrimer surfaces hydrophobic. The conjugates were dissolved in the mobile phase (90:10 water/ACN). The injection volume was $500 \mu \mathrm{L}$ with a sample concentration of approximately $5 \mathrm{mg} / \mathrm{mL}$, and the detection of eluted samples was performed at 210 and $488 \mathrm{~nm}$.

\section{Absorption and Emission Measurements}

Fluorescence (Fluoromax-4) and UV-vis (Shimadzu UV-1601) measurements were taken at a concentration of $0.05 \mathrm{mg} / \mathrm{mL}$. For all measurements, the concentration of the solutions were $0.05 \mathrm{mg} / \mathrm{mL}$ and within an error of \pm 0.02 . For the fluorescence measurements an excitation of $488 \mathrm{~nm}$ and emission of $525 \mathrm{~nm}$ were used with a slit width of $2 \mathrm{~nm}$.

\section{Zeta Potential Measurements}

A Malvern Zetasizer Nano ZS (Worchestershire, U.K) instrument with a $4 \mathrm{~mW} \mathrm{He}-\mathrm{Ne}$ laser operating at $633 \mathrm{~nm}$ with a $173^{\circ}$ scattering angle was used to measure particle zeta potential. The refractive index used for the measurements was 1.59. Data from 3 measurements each consisting of 20 repeats were made on $0.05 \mathrm{mg} / \mathrm{mL}$ solutions. 


\section{MALDI-TOF-MS Measurements}

Three solutions were prepared: (1) $10 \mathrm{mg} / \mathrm{mL}$ dendrimer in water, (2) $20 \mathrm{mg} / \mathrm{mL}$ sinnipinic acid in $1: 1(\mathrm{v} / \mathrm{v})$ acetonitrile: water, and (3) $20 \mathrm{mg} / \mathrm{mL}$ sodium trifluoroacetate in water. These were then combined in a ratio of 10:2:1 of matrix:dendrimer:salt solution. The plate was spotted with $1 \mu \mathrm{L}$ volumes of solution and allowed to dry. At least 100 scans were averaged per measurement.

\section{Quantifying Cellular Uptake of G3-OG $n\left(n=1,2,3,4+, 4_{\text {avg }}\right)$ for HEK 293A Cells}

HEK 293A cells were seeded in 24 well plates (Fisher Scientific, $3.8 \mathrm{~cm}^{2}$ ) at a density of 100000 cells per well in $0.5 \mathrm{~mL}$ of complete DMEM incubated overnight at $37{ }^{\circ} \mathrm{C}$ with $5 \%$ $\mathrm{CO}_{2}$. Prior to incubation with $\mathrm{G} 3-\mathrm{OG}_{n}$, the complete media was removed. The cells were then rinsed with $1 \mathrm{~mL}$ of PBS, followed by addition of $0.3 \mathrm{~mL}$ of complete DMEM. The cells were incubated for $24 \mathrm{~h}$ at $37{ }^{\circ} \mathrm{C}$ with $5 \mu \mathrm{M} \mathrm{G} 3-\mathrm{OG}_{n}(n=1-3,4+, 4)(\sim 7.0 \mu \mathrm{L}$ volume of $2 \mathrm{mg} / \mathrm{mL}$ solution added to each well). Each treatment was run in triplicate and 2 independent biological repeats were performed. After incubation with $\mathrm{G} 3-\mathrm{OG}_{\mathrm{n}}$ material, the HEK 293A cells were rinsed with PBS and harvested for flow cytometry by trypsinization. Trypsinization was performed by incubation with $200 \mu \mathrm{L}$ of trypsin for 2 min at $37{ }^{\circ} \mathrm{C}$. After $2 \mathrm{~min}, 0.8 \mathrm{~mL}$ of cold PBS was added to each well to inhibit the trypsin, and the suspensions were then centrifuged for $5 \mathrm{~min}$ at $2000 \mathrm{rpm}$. Cell pellets were resuspended in $400 \mu \mathrm{L}$ of PBS. Cell fluorescence was measured using a BD C6 Accuri flow cytometer by collecting 10000 events per sample. The cells were excited using a $488 \mathrm{~nm}$ laser and emission at the $525 \pm 20 \mathrm{~nm}$ region was measured. Differences were determined according to a post hoc Games-Howell test using predictive analytics SPSS software. This statistical test was chosen because it does not assume equal variance, which we deemed most relevant for comparing multiple biological replicates of HEK 293A cells (* indicates a $p$ value $<0.05$ ).

\section{Quantifying Cellular Uptake of G3-OG $n\left(n=1,2,3,4+, 4_{\text {avg }}\right)$ for RAW264.7 Cells}

RAW cells were seeded in 24 well plates (Fisher Scientific, $3.8 \mathrm{~cm}^{2}$ ) at a density of 100,000 cells per well in $0.5 \mathrm{~mL}$ of complete RPMI incubated overnight at $37^{\circ} \mathrm{C}$ with $5 \% \mathrm{CO}_{2}$. Prior to incubation with $\mathrm{G} 3-\mathrm{OG}_{n}$, the complete media was removed. The cells were then rinsed with $1 \mathrm{~mL}$ of PBS, followed by addition of $0.3 \mathrm{~mL}$ of complete RPMI. The cells were incubated for $24 \mathrm{~h}$ at $37^{\circ} \mathrm{C}$ with $5 \mu \mathrm{M} \mathrm{G} 3-\mathrm{OG}_{n}(n=1-3,4+, 4)(\sim 7.0 \mu \mathrm{L}$ volume of 2 $\mathrm{mg} / \mathrm{mL}$ solution added to each well). Each treatment was run in triplicate and 2 independent biological repeats were performed. After incubation with $\mathrm{G} 3-\mathrm{OG}_{\mathrm{n}}$ material, the RAW cells were rinsed with PBS and harvested for flow cytometry by scraping. Cell pellets were resuspended in $400 \mu \mathrm{L}$ of FACS buffer. Cell fluorescence was measured using a BD C6 Accuri flow cytometer by collecting 10,000 events per sample. The cells were excited using a $488 \mathrm{~nm}$ laser and emission at the $525 \pm 20 \mathrm{~nm}$ region was measured. Differences were determined according to a post hoc Games-Howell test using predictive analytics SPSS software. This statistical test was chosen because it does not assume equal variance, which we deemed most relevant for comparing multiple biological replicates of HEK 293A cells (* indicates a $p$ value $<0.05$ ). 


\section{Supplementary Material}

Refer to Web version on PubMed Central for supplementary material.

\section{Acknowledgments}

S.N.G. was supported by grant funding from the National Heart, Lung, and Blood Institute of the NIH (K08HL123621). S.D. was funded by the NIH BUILD Project Pathways grant (8UL1GM118967-02) and the NSF EPSCoR Track 2 grant (IAA-1430280) as well as an NIMHD-RCMI grant (5G12MD007595) from the National Institute on Minority Health and the Louisiana Cancer Research Consortium. The contents are solely the responsibility of the authors and do not necessarily represent the official views of the NIH.

\section{References}

1. Aikawa E, Nahrendorf M, Figueiredo JL, Swirski FK, Shtatland T, Kohler RH, Jaffer FA, Aikawa M, Weissleder R. Osteogenesis associates with inflammation in early-stage atherosclerosis evaluated by molecular imaging in vivo. Circulation. 2007; 116:2841-2850. [PubMed: 18040026]

2. Buono C, Anzinger JJ, Amar M, Kruth HS. Fluorescent pegylated nanoparticles demonstrate fluidphase pinocytosis by macrophages in mouse atherosclerotic lesions. J Clin Invest. 2009; 119:13731381. [PubMed: 19363293]

3. Benakis C, Garcia-Bonilla L, Iadecola C, Anrather J. The role of microglia and myeloid immune cells in acute cerebral ischemia. Front Cell Neurosci. 2015; 8:461. [PubMed: 25642168]

4. Gaglia JL, Harisinghani M, Aganj I, Wojtkiewicz GR, Hedgire S, Benoist C, Mathis D, Weissleder R. Noninvasive mapping of pancreatic inflammation in recent-onset type-1 diabetes patients. Proc Natl Acad Sci U S A. 2015; 112:2139-2144. [PubMed: 25650428]

5. Dai H, Navath RS, Balakrishnan B, Guru BR, Mishra MK, Romero R, Kannan RM, Kannan S. Intrinsic targeting of inflammatory cells in the brain by polyamidoamine dendrimers upon subarachnoid administration. Nanomedicine. 2010; 5:1317-1329. [PubMed: 21128716]

6. Kannan S, Dai H, Navath RS, Balakrishnan B, Jyoti A, Janisse J, Romero R, Kannan RM. Dendrimer-Based Postnatal Therapy for Neuroinflammation and Cerebral Palsy in a Rabbit Model. Sci Transl Med. 2012; 4:130ra46.

7. Weissleder R, Nahrendorf M, Pittet MJ. Imaging macro-phages with nanoparticles. Nat Mater. 2014; 13:125-138. [PubMed: 24452356]

8. Kou L, Sun JJ, Zhai Y, He Z. The endocytosis and intracellular fate of nanomedicines: Implication for rational design. Asian J Pharm Sci. 2013; 8:1-10.

9. Swanson JA. Shaping cups into phagosomes and macropinosomes. Nat Rev Mol Cell Biol. 2008; 9:639-649. [PubMed: 18612320]

10. Swanson JA, Watts C. Macropinocytosis. Trends Cell Biol. 1995; 5:424-428. [PubMed: 14732047]

11. Lim JP, Gleeson PA. Macropinocytosis: an endocytic pathway for internalising large gulps. Immunol Cell Biol. 2011; 89:836-843. [PubMed: 21423264]

12. Mercer J, Helenius A. Gulping rather than sipping: macropinocytosis as a way of virus entry. Curr Opin Microbiol. 2012; 15:490-499. [PubMed: 22749376]

13. Marechal V, Prevost MC, Petit C, Perret E, Heard JM, Schwartz O. Human immunodeficiency virus type 1 entry into macrophages mediated by macropinocytosis. J Virol. 2001; 75:1116611177. [PubMed: 11602756]

14. Lundqvist M, Stigler J, Elia G, Lynch I, Cedervall T, Dawson KA. Nanoparticle size and surface properties determine the protein corona with possible implications for biological impacts. Proc Natl Acad Sci U S A. 2008; 105:14265-14270. [PubMed: 18809927]

15. Lynch I, Dawson KA. Protein-Nanoparticle Interactions. Nano Today. 2008; 3:40-47.

16. Monopoli MP, Aberg C, Salvati A, Dawson KA. Biomolecular coronas provide the biological identity of nanosized materials. Nat Nanotechnol. 2012; 7:779-786. [PubMed: 23212421]

17. Akesson A, Cardenas M, Elia G, Monopoli MP, Dawson KA. The protein corona of dendrimers: PAMAM binds and activates complement proteins in human plasma in a generation dependent manner. RSC Adv. 2012; 2:11245-11248. 
18. van Dongen M, Dougherty CA, Banaszak Holl MM. Multivalent Polymers for Drug Delivery and Imaging: The Challenges of Conjugation. Biomacromolecules. 2014; 15:3215-3234. [PubMed: 25120091]

19. Verma A, Stellacci F. Effect of Surface Properties on Nanoparticle-Cell Interactions. Small. 2010; 6:12-21. [PubMed: 19844908]

20. Yoo H, Juliano RL. Enhanced delivery of antisense oligonucleotides with fluorophore-conjugated PAMAM dendrimers. Nucleic Acids Res. 2000; 28:4225-4231. [PubMed: 11058121]

21. Dougherty CA, Furgal JC, Van Dongen MA, Goodson T, Banaszak Holl MM, Manono J, Di Maggio S. Isolation and Characterization of Precise/Dye Dendrimer Ratios. Chem Eur J. 2014; 20:4638-4645. [PubMed: 24604830]

22. Dougherty CA, Vaidyanathan S, Banaszak Holl MM. Fluorophore:Dendrimer Ratio Impacts Cellular Uptake and Fluorescence Lifetime. Bioconjugate Chem. 2015; 26:304-315.

23. Manono J, Dougherty CA, Jones K, De Muth J, Banaszak Holl MM, Di Maggio S. Generation 3 PAMAM Dendrimer TAMRA Conjugates Containing Precise Dye/Dendrimer Ratios. Mater Today Commun. 2015; 4:86-92.

24. Mullen DG, Desai A, van Dongen MA, Barash M, Baker JR, Banaszak Holl MM. Best Practices for Purification and Characterization of PAMAM Dendrimer. Macromolecules. 2012; 45:53165320. [PubMed: 23180887]

25. van Dongen MA, Desai A, Orr BG, Baker JR, Banaszak Holl MM. Quantitative Analysis of Generation and Branch Defects in G5 Poly(amidoamine) Dendrimer. Polymer. 2013; 54:41264133. [PubMed: 24058210]

26. Harush-Frenkel O, Rozentur E, Benita S, Altschuler Y. Surface charge of nanoparticles determines their endocytic and transcytotic pathway in polarized MDCK cells. Biomacromolecules. 2008; 9:435-443. [PubMed: 18189360]

27. Sahay G, Alakhova DY, Kabanov AV. Endocytosis of nanomedicines. J Controlled Release. 2010; 145:182-195.

28. Kannan RM, Nance E, Kannan S, Tomalia DA. Emerging concepts in dendrimer-based nanomedicine: from design principles to clinical applications. J Intern Med. 2014; 116:579-617.

29. Tomalia DA, Khanna S. A Systematic Framework and Nanoperiodic Concept for Unifying Nanoscience: Hard/Soft Nanoelements, Superatoms, Meta-Atoms, New Emerging Properties, Periodic Property Patterns, and Predictive Mendeleev-like Nanoperiodic Tables. Chem Rev. 2016; 116:2795-2774. 
A

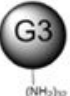

$\mathrm{NH}_{2}$

C

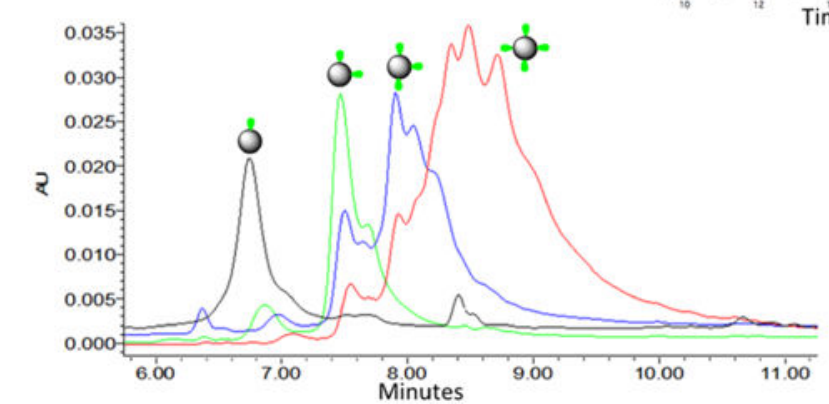

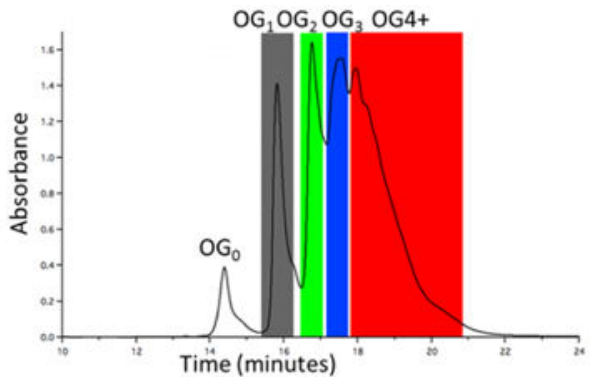

Figure 1.

(A) Synthesis scheme for G3-OG conjugates. (B) Isolation of G3-OG-NHAc dendrimers using rpHPLC. (C) UPLC traces of G3-OG isolation. 

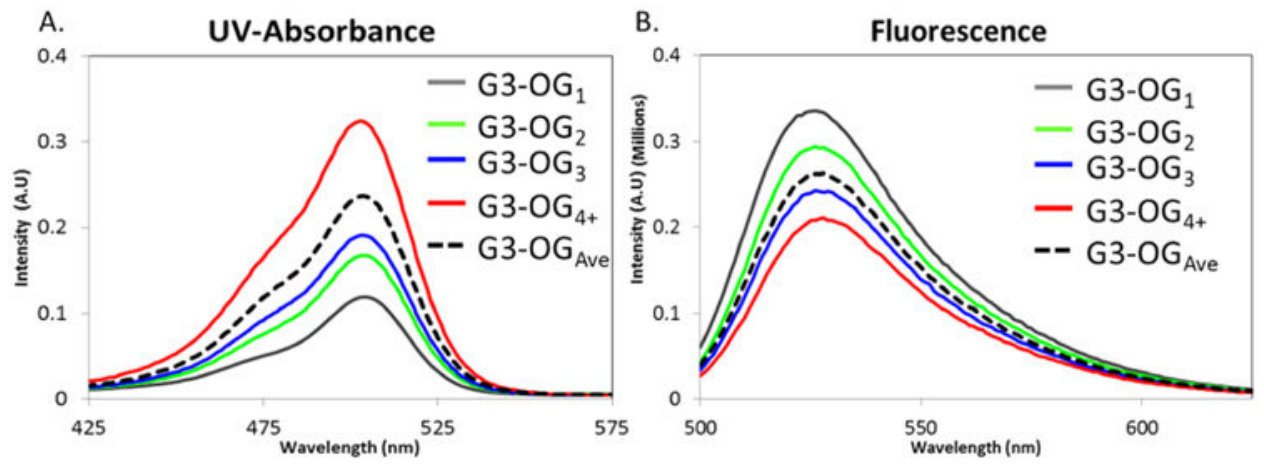

Figure 2.

(A) UV absorption of G3-PAMAM-OG ${ }_{n}$ (B) Fluorescence emission of G3-OG-NHAc species. 
A

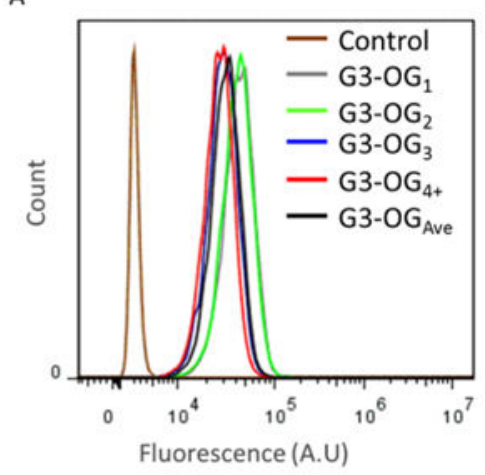

C

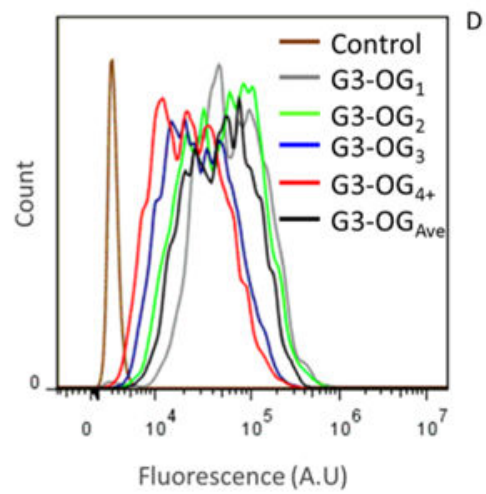

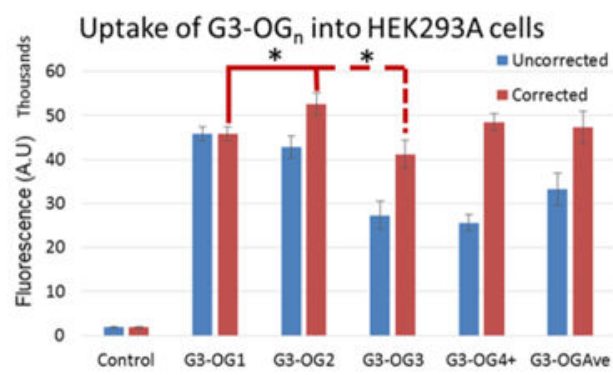

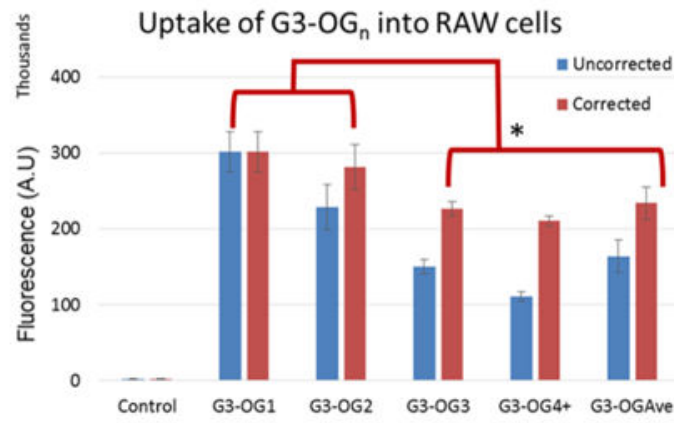

Figure 3.

(A) Uncorrected uptake of $\mathrm{G} 3-\mathrm{OG}_{n}(n=1-4+$, Average) in HEK 293A cells as measured by flow cytometry. (B) Uncorrected and corrected mean fluorescence values for HEK 293A cells. (C) Uncorrected uptake of G3-OG - -Ac ( $n=1-4+$, Average) in RAW cells. (D) Uncorrected and corrected mean fluorescence values for RAW cells. 


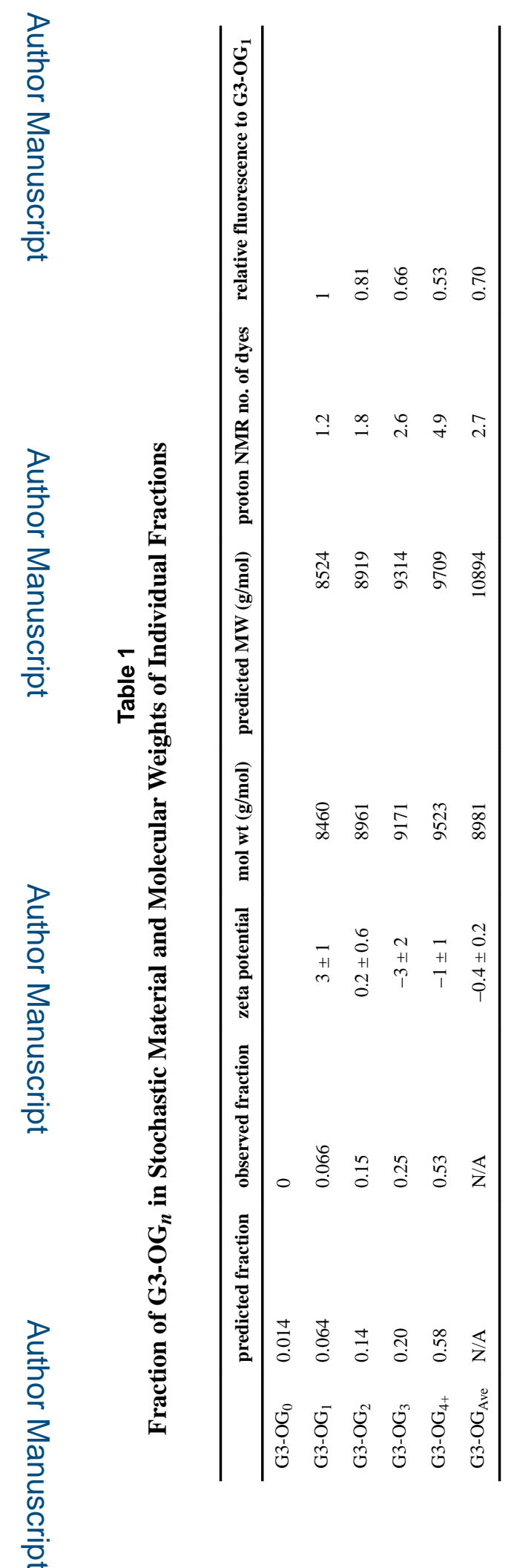

ACS Biomater Sci Eng. Author manuscript; available in PMC 2017 September 12. 